\title{
QUALITATIVE IMPORTANCE MEASURES OF SYSTEMS COMPONENTS - A NEW APPROACH AND ITS APPLICATIONS
}

\author{
Leszek CHYBOWSKI, Katarzyna GAWDZIŃSKA, Bogusz WIŚNICKI \\ Maritime University of Szczecin
}

\begin{abstract}
:
The paper presents an improved methodology of analysing the qualitative importance of components in the functional and reliability structures of the system. We present basic importance measures, i.e. the Birnbaum's structural measure, the order of the smallest minimal cut-set, the repetition count of an i-th event in the Fault Tree and the streams measure. A subsystem of circulation pumps and fuel heaters in the main engine fuel supply system of a container vessel illustrates the qualitative importance analysis. We constructed a functional model and a Fault Tree which we analysed using qualitative measures. Additionally, we compared the calculated measures and introduced corrected measures as a tool for improving the analysis. We proposed scaled measures and a common measure taking into account the location of the component in the reliability and functional structures. Finally, we proposed an area where the measures could be applied.
\end{abstract}

Key words: Fault Tree Analysis, component importance, qualitative analysis, functional structure, reliability structure, marine power plant system

\section{INTRODUCTION}

The man uses complex technical systems in undertaken activities, frequently becoming their components. In the family of systems that we can find technical systems play a significant role. A sea-operated vessel is an example of such a system.

Every technical system has important components in its structure which need to be identified. In 1941 Juran used the Pareto Principle in his studies on production quality and observed that $80 \%$ of the effects come from $20 \%$ of the causes. The research on the importance of components in technical systems has shown so far that important components make about $20 \%$ of all system components and simultaneously they decide in $80-85 \%$ about the system reliability [14].

The importance analysis intends to determine which component is the most important for the functioning of the system to ensure an optimal value of a particular dependability measure, e.g. the system availability, expected number of failures, or relative likelihood of causing the system failure [19].

The importance analysis can be used to:

- identify critical system components [15],

- determine qualitative and quantitative reliability characteristics [29],

- support system design and evaluate the changes in designed products,

- optimize the use of resources,

- evaluate quality (verify components, certify products, evaluate technical solutions and operational procedures),
- find genesis, diagnose and forecast the state of processes and machinery [28],

- analyse risk, monitor and control exploitation safety,

- investigate accidents (degradation processes, human factor, interactions with the environment),

- make a common cause analysis.

By far qualitative and quantitative component importance analysis has usually been made using a fault tree. Table 1 presents the most famous projects where qualitative methods were applied.

The transportation system is highly reliable owing to safe and effective operation of ships which are a basic means of global transportation [6, 23]. In 2012, ships transported over $80 \%$ of the world volume of goods. Functional subsystems of ships are components of the transportation system. Apart from typical transport ships, a large group of ships performs special tasks such as: oil and gas extraction, deep-sea fishery, pipe and cable laying etc. The power plant contributing to a ship reliable operation is its elementary subsystem, i.e. it is a set of machines and devices designed for generating mechanical, electrical and heat energy [4].

Using modern technical solutions to improve the safety of exploitation by e.g. introducing the so called unmanned engine rooms [6], modern materials [12] and improved operational procedures, results in a construction complexity [7] of a power plant but provides its higher reliability. Additionally, the progress in materials science and engineering, new methods in technical diagnostics and improved maintenance procedures provide higher ship reliability and durability and shorter idle time in ship operation (mean time to repair). This in turn extends mean time between failures and lowers the overall costs of spare parts during ship operation [4]. 
Selected application of fault tree analysis and methods of qualitative importance analysis

\begin{tabular}{|c|c|}
\hline Industry/sector & Selected applications \\
\hline Aeronautics & $\begin{array}{l}\text { Passenger planes (e.g. Boeing 737, } 757 \text { and 767), fighters, bombers, airtankers, helicopters, } \\
\text { space stations, satellites, lunar roving vehicles (Apollo projects), space shuttles, rocket launch } \\
\text { systems (Minuteman, Tomahawk, SRAM, ALCM) etc. }\end{array}$ \\
\hline Power engineering & $\begin{array}{c}\text { Nuclear, solar and conventional power plants, emergency supply systems, power transmission } \\
\text { and distribution }\end{array}$ \\
\hline Transport systems & Railway systems, waterborne and road transport \\
\hline $\begin{array}{l}\text { Chemical technology } \\
\text { and engineering }\end{array}$ & Production of hydrocarbons, fertilisers, semi-finished products for the food processing industry \\
\hline Automation and robotics & Control systems for production lines, Torpedo launching doming systems \\
\hline $\begin{array}{l}\text { Deep sea mining } \\
\text { and ocean engineering }\end{array}$ & Offshore platforms, Floating Production, Storage and Offloading Units, tankers \\
\hline $\mathrm{ICT}$ & Software system safety andcomputer network analysis \\
\hline
\end{tabular}

Source: $[5,10]$.

Although the reliability of ship technical systems has improved, maritime disasters still happen and they result in: loss of life of passengers and crew and material damage connected with serious ship breakdown or sinking. For instance, according to the statistical data provided for year 2012 by the Allianz Group, by 25 November 106 ships had been reported lost - that is $16 \%$ more cases when compared to the previous year 2011 (91 ships) but 27\% fewer in comparison to a 10-year average number of lost vessels equal to 146 ships reported in one year [23]. The consequences of such events might be very serious, let the case of Costa Concordia, an Italian cruise ship running aground off an Italian coast, or Rabaul Queen, capsized near Papua New Guinea, be their most illustrative examples both causing loss of life.

Considering that, it is extremely significant to analyse the importance of components (failure impact) for subsystems like ships and their propulsion systems referring to the functions of the system. This analysis makes it possible to detect the connected system components whose interactions might lead to safety threat and breakdown of the whole system or its part [18, 20].

Further in the paper, we made an overview of popular qualitative measures of importance, we proposed how to normalize them, we compared them, and introduced a combined measure considering different criteria.

\section{IMPORTANCE OF THE COMPONENT}

From a general point of view, an important component is one that has the appropriate set of characteristic relative to properties with values adopted a priori within an acceptable range of variability. Maciej Woropay [27] defined importance as the ability to reach the "vertical impact" (in terms of child and parent system relations) of damage to the child system with the concerned level of decomposition to reduce the possibility of the task accomplishment by parent systems. The importance to the system therefore is a function of fulfilling requirements defined by $\mathrm{k}_{\mathrm{q}}$ criteria:

$$
I=f\left(k_{1}, k_{2}, \ldots k_{q} \ldots k_{n_{k}}\right), q=1,2 \ldots n_{k}
$$

The importance of system components may be determined by a set of criteria. The greater the number of criteria, the more detailed the analysis of the component's importance (child system) to system functioning. The concept of "weight of evaluation criteria" (hereinafter referred to as relevance criteria) is to be found in the literature [16], and must be distinguished from the "importance criteria".

The relevance of the criteria refers to the selection of specific criteria and an appropriate degree of their inclusion in the specific measures of the definition of importance. This approach is useful in assessing the first phase of system component importance, which is the selection of importance criteria and measures of importance based on these criteria. The literature [16] (including indicators of process quality) describes many characteristics presented in Table 2 in relation to the concept of relevance criteria. Most of these characteristics may also function as base criteria for assessing the importance of elements in the complex technical system reliability structure.

If the functional state of the system assigns a defined number to each $f$ function of function space, then a criterion for the analysis of importance consists of whether or not the assigned value of is within the specified range of acceptable variation [27]:

$$
a \leq \Phi(f) \leq b
$$

Importance in terms of reliability is intended to determine the most important component for the functioning of the system to ensure optimal value of a particular dependability measure - for example, to determine which component has the biggest impact on changing the value of system readiness, expected for damage to occur, or relative likelihood of causing system failure. The concept of component importance is closely linked to the concept of sensitivity, and these terms are sometimes used interchangeably in the literature. Sensitivity is defined as the partial derivative of the system reliability function with respect to reliability of the i-th component of the system. This definition is synonymous to the Birnbaum's Reliability importance measure $[1,2]$ :

$$
P_{i}^{D}=\frac{\partial R}{\partial r_{i}}
$$

According to Equation (3.3), the component importance depends on two basic factors:

- the reliability characteristics of the system components,

- the system reliability structure. 


\begin{tabular}{llll}
\hline No & \multicolumn{1}{c}{ Name } & Letter code & \multicolumn{1}{c}{ What does the criterion inform about? } \\
\hline 1 & Safety & B & About safety or risk to health or life \\
2 & Benefit & L & About benefits or effects achieved \\
3 & Cost & K & About costs incurred \\
4 & Reliability & N & About reliability, the failure rateor improper operation \\
5 & Novelty & C & About novelties, modernity, vogue or time factor \\
6 & Effectiveness & S & About proper execution of projected tasks \\
7 & Pertinence & T & About purpose and compliance with specifications \\
8 & Usability & U & About durability, course and time of use \\
9 & Defectiveness & W & About defects, malfunctions and workmanship \\
10 & Appearance & P & About harmony of shape, colours and aesthetic impressions \\
\hline
\end{tabular}

Source: [16].

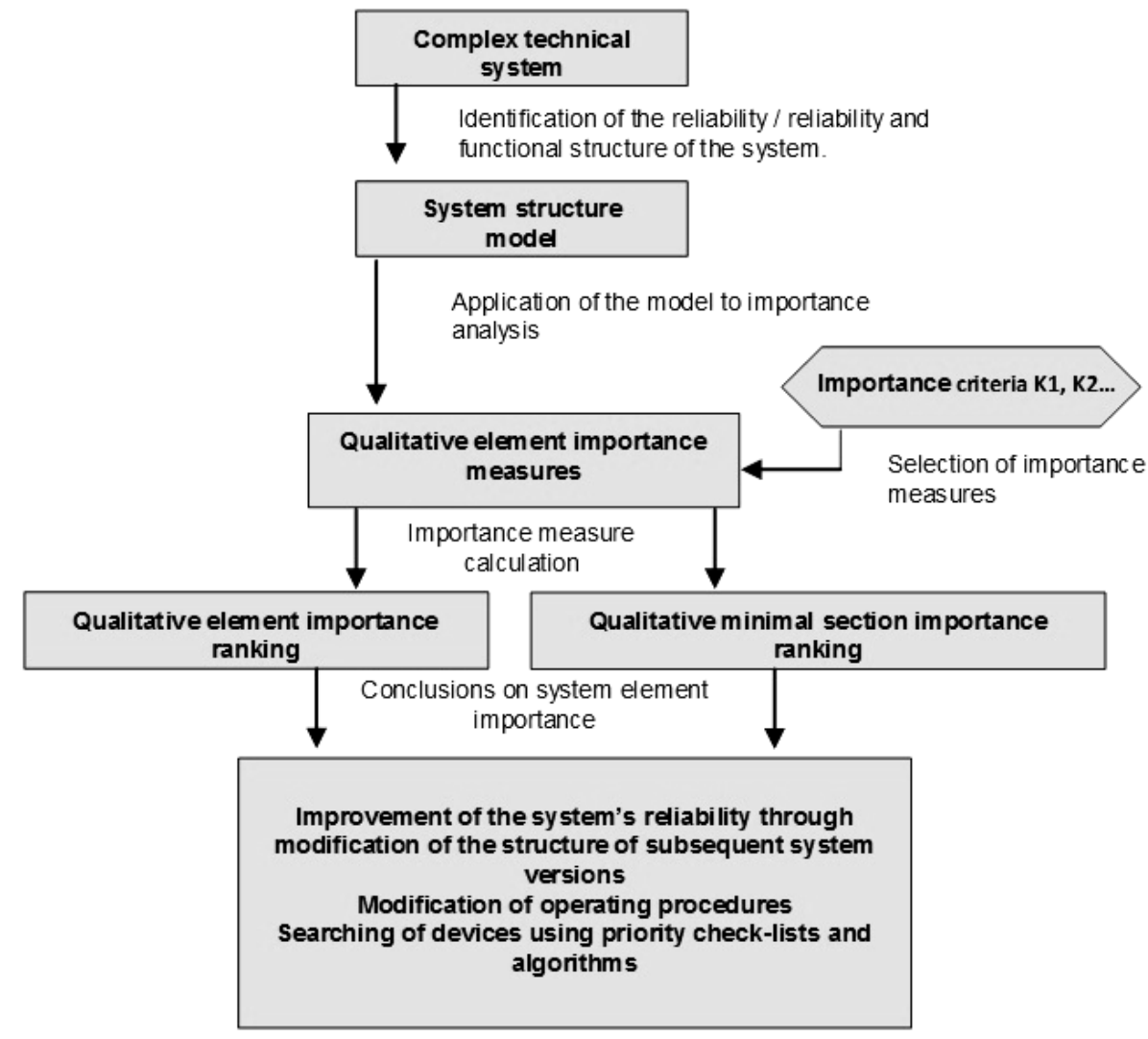

Fig. 1 Qualitative analysis of complex technical systems component importance Source: [4].

A qualitative analysis of a system consists of a minimal cut-sets and path-sets finding process, and a fault tree model representation in the form of reduced Boolean equations [21]. Results of operations described above allow drawing conclusions about the complex technical system reliability structure [8]. Depending on its location in the structure, particular components will have a different impact on the proper functioning of the system as a function of the mutual relations between these elements.

Figure 1 shows the process of qualitative analysis of component importance. According to the illustration, for the technical system analysed, a representation of the reliability structure (structure model) can be obtained as a result of the identification process and system modelling.

The next step is the selection of importance measures and their application to the structure of the reliability model, which produces an estimate of selected measurement importance and the importance rating of system components for each measurement. Conclusions about the construction of the analysed technical system, and the efficiency of the implemented operating procedures, can be drawn on the basis of the results obtained. 


\section{QUALITATIVE IMPORTANCE EVALUATION}

The importance of the minimal cut-set often depends on the number of system components [24]. In general, the smaller the minimal cut-set, the closer its components are to standalone units and a serial system structure. The quantity of the minimal cut-set is called its "order." The rate of increase of the minimal cutset order is associated with a decrease of the cut-set components' importance. If a specific component is present in many minimal cut-sets, the first cut-set for the analysis is that with the smallest order. The order of the smallest minimal cut-set containing the i-th component can be described as follows [25]:

$$
I_{i}^{O}=\min _{k=1 i, 2 i, \ldots n i}\left[\operatorname{card}\left(C_{k}\right)\right]
$$

where:

$\mathrm{C}_{1 \mathrm{i}}, \mathrm{C}_{2 \mathrm{i}}, \ldots, \mathrm{C}_{\mathrm{ni}}$ - set of all minimal cut-sets containing $\mathrm{i}$-th component.

Another qualitative measure of the importance is a repetition count of an i-th event in the Fault Tree modelling the effects of faults in the system.

This measure assumes the importance of a component increases with the number of times it appears in the Fault Tree. It could be applied to bridge joint and threshold structures, where events describing damage to certain components occur repeatedly. Before determining the value of this indicator, it is necessary to convert logic gates k-of-n into a sum of disjoint products. An illustration of such a conversion is shown in Figure 2, the Fault Tree example containing the gateway 2-of-3.

The conversion tree shown in Figure $2 a$ allows to achieve an equivalent (substitute) Fault Tree created with only one logical disjunction for which inputs are connected with logical conjunctions of primary events (Fig. 2b). Sets of input events for each logical disjunction are cut-sets of the system. After exclusion of cut-sets containing other minimal cut-sets from these sets, the result is the set of minimal cutsets of the system (Fig. 2c).

The measure could be represented as $[25,26]$ :

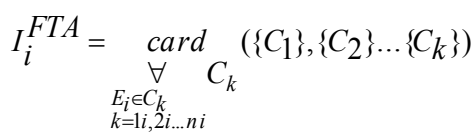

a)

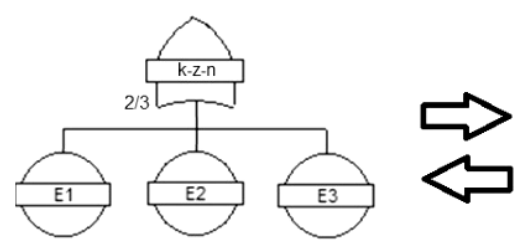

where:

$\mathrm{C}_{1 \mathrm{i}}, \mathrm{C}_{2 \mathrm{i}}, \ldots, \mathrm{C}_{\mathrm{ni}}$ - the set of all minimal cut-sets containing the i-th component component.

The structural Birnbaum's measure could be defined as the relative count of system states, for which the i-th component is critical to the system. Available literature contains various definitions of criticality, including "vulnerability to sudden changes of physical state resulting in damage". Such a definition refers to a critical component as the one, for which a fault causes a system fault [25]. Such an approach assumes all components of serial reliability structure are critical. The vector of critical path for the i-th component is each state vector of other system components which is operational only when the i-th component is also operational. This measure could be defined by the following equation [25]:

where:

$$
I_{i}^{B s}=\frac{v(i)}{2^{n-1}}
$$

$v$ (i) - the total number of critical path vectors for i-th component,

$\mathrm{n}$ - the total number of system components.

The structural Birnbaum's measure determines the relative number of system states (for all components other than the i-th one), which set the status of $i$-th component as the critical. If the unavailability value $q_{i}$ of this function for all system components equals 0.5 , then following equation is valid [2]:

$$
I_{i}^{B s}=\frac{\partial Q[\vec{q}]}{\partial q_{i}}
$$

where:

$Q[\vec{q}]$ - system unavailability value,

$\vec{q}=\left[q_{1}, q_{2}, \ldots, q_{n}\right]=[\underbrace{0.5 ; 0.5 ; \ldots 0.5}_{n \text { times }}]-$ vector of system

unavailability,

$q_{i}$ - unavailability of the $i$-th component.

Different qualitative criteria of importance have been proposed in the literature $[3,11,13]$. One such measure is based on the location of the component in the system's functional structure. This indicator could be defined as the measure of $\mathrm{I}^{\mathrm{KM}}$ streams, being the sum of the number of energetic mediums $s^{\mathrm{IN}}$ (flowing in) and $s^{\text {OUT }}$ (flowing out) from the i-th component (device) if the technical system [17].

b)

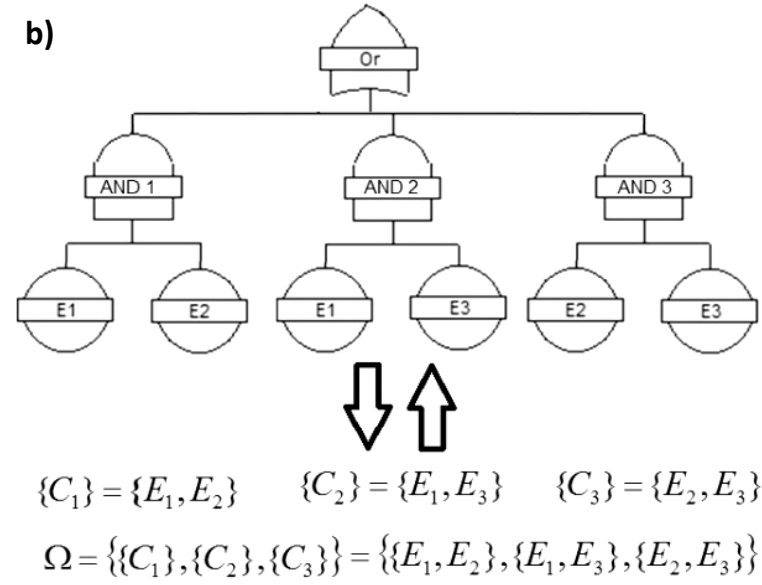

Fig. 2 Illustration of $k$-of-n gates conversion method: 
This measure can be represented as follows:

$$
I_{i}^{K M}=s_{i}^{I N}+s_{i}^{O U T}
$$

where:

$s^{\mathrm{IN}}$ - the number of energetic mediums flowing in the i-th component,

$\mathrm{s}^{\text {OUT }}$ - the number of energetic mediums flowing out the ith component.

This measure is inconclusive because the number of individual streams flowing in and out may vary as a result of an analysis which includes other sub-functions and system component operation models for drainage, venting, auxiliary power systems, and energy fields. Even so, this measure has the advantage of creating the association of components of an n-component subsystem with other subsystems by taking power connections between systems into account. After normalization of the streams measure to a value range of [0.1]:

$$
I_{i}^{C M}=k_{C} I_{i}^{K M}
$$

where:

$k_{C}=\left[\sum_{l=1}^{n} I_{l}^{K M}\right]^{-1}-$ factor summing to one,

$\mathrm{I}^{\mathrm{KM}}-$ measure of streams.

\section{OBJECT OF THE ANALYSIS}

All of these qualitative measures may be used during the initial phase of exploitation safety or reliability of the ship's propulsion system analysis. Figure 3 is a diagram of a fuel supply system for the main engine of a common container ship, with a capacity of 6500 TEU [22]. The purpose of the system is to fuel the main engine with the required quantity of fuel containing the correct parameters (purity, kinematic viscosity) [7]. At any given time only one supply pump and one circulation pump operate in the system; all remaining pumps are offline, and function as spare components in the system as a whole. The supply pump draws the fuel from the day fuel tank through set of filters, and pumps it to the circulation pump intake (P1 or P2), which then delivers it through heater $(\mathrm{H} 1$ or $\mathrm{H} 2)$ to the injection system of the main engine.

Components of the system, set off by the green box in Figure 3, will be used as an example of an application for a set of qualitative measures of importance. A view of circulation pumps that are the part of the subsystem analysed is shown in Figure 4.

A surplus amount of unused fuel is rerouted from the main engine to the vented return tank, from which the fuel is delivered to the intake side of the circulation pumps (P1, $P 2)$. Excess fuel in the tank is returned to the daily fuel tank.

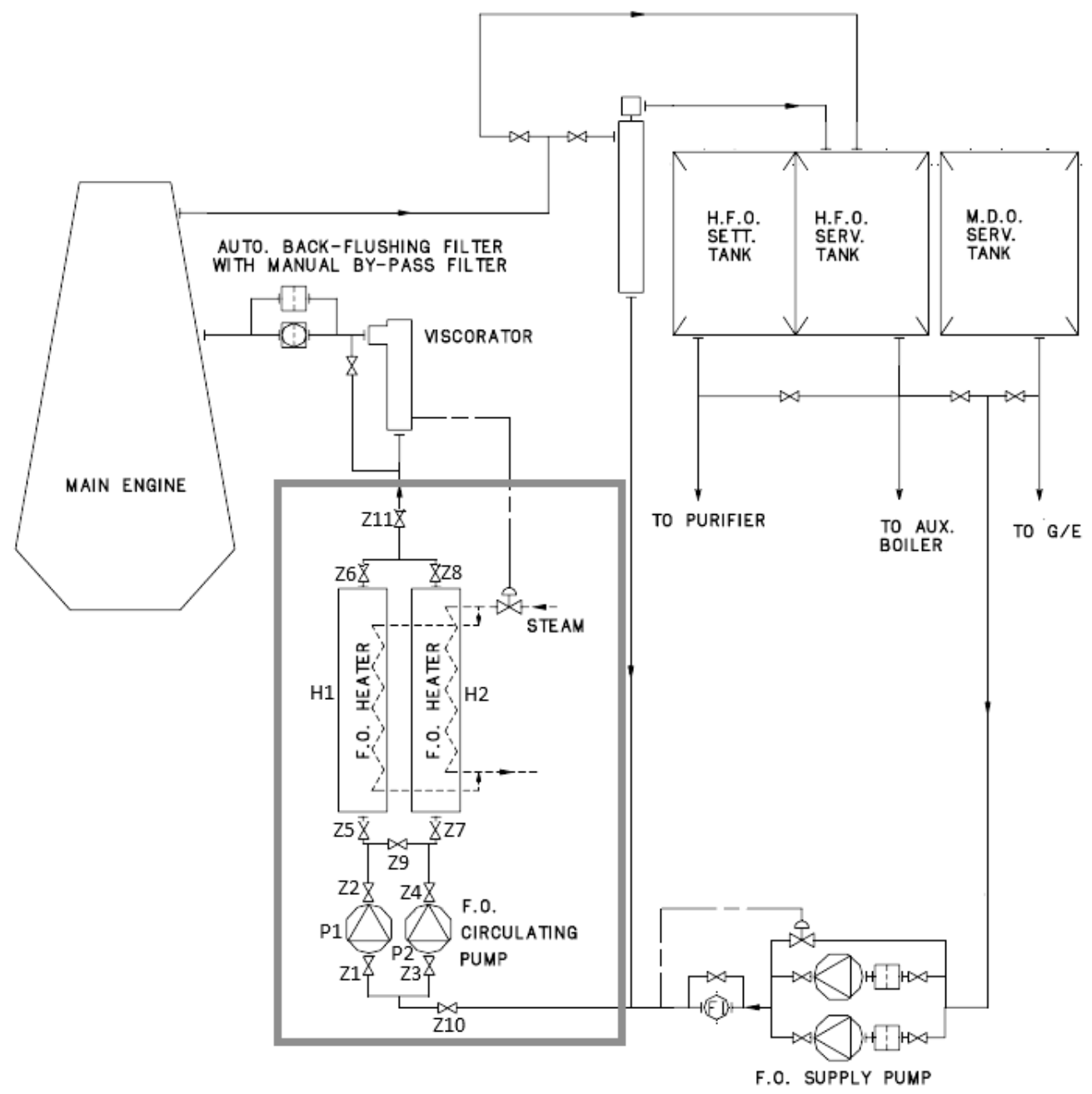

Fig. 3 Fuel system for main engine of a 6500 TEU container ship (description in the text)

Source: [22]. 


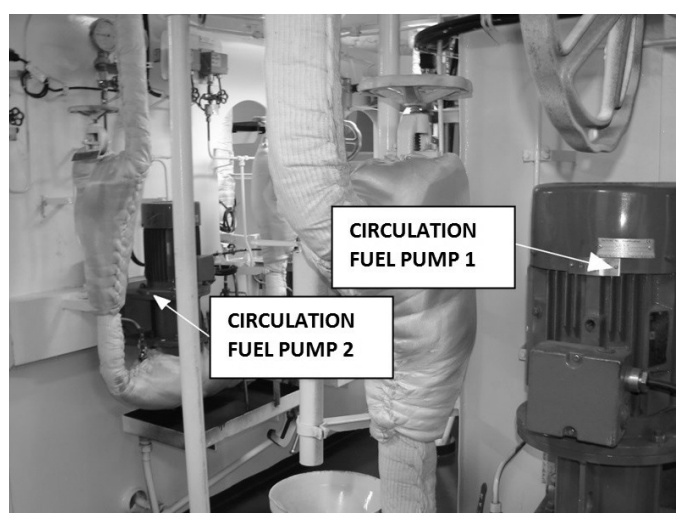

Fig. 4 View of main engine fuel system circulation pumps

Source: [4].

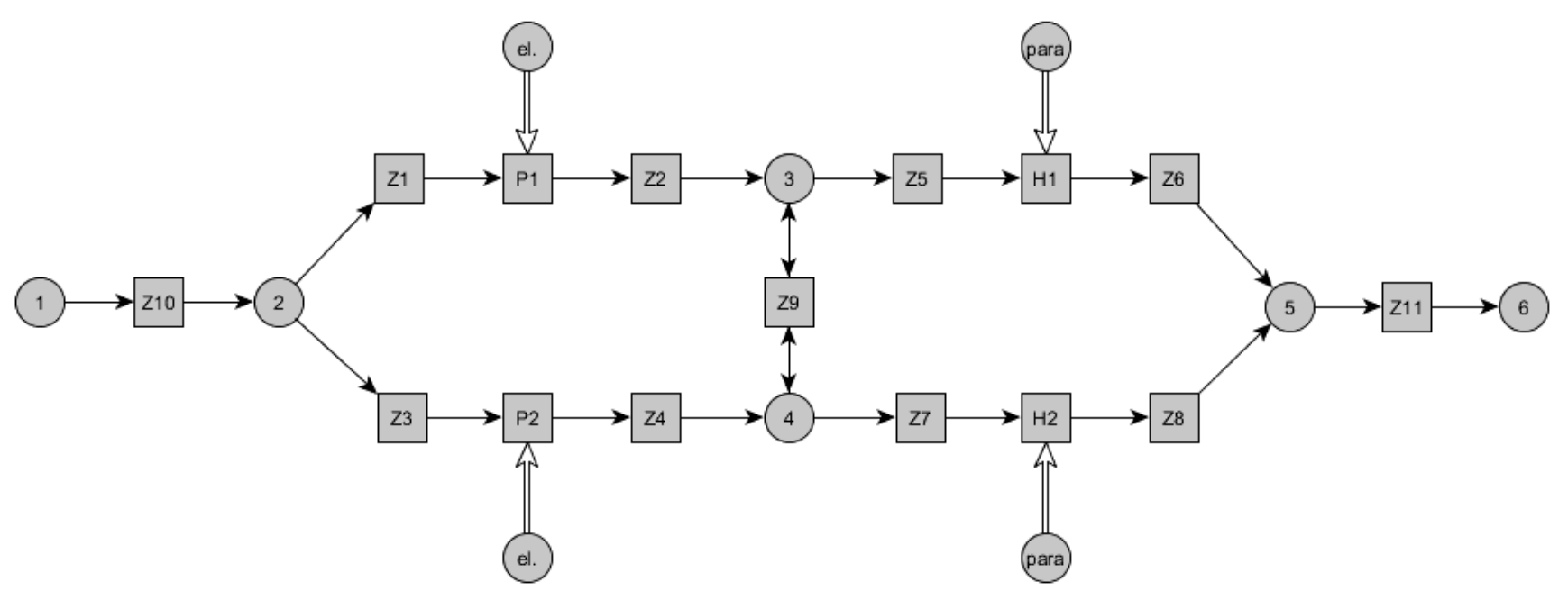

Fig. 5 Functional structure of circulation pump subsystem and main engine fuel system heater subsystem of a common 6500 TEU container ship (description in the text)

Source: [4].

The fuel is heated before it reaches the engine to ensure it is has the right kinematic viscosity $\left(12 \div 15 \mathrm{~mm}^{2} / \mathrm{s}\right)$ to be sprayed inside the cylinders. Heaters $(\mathrm{H} 1, \mathrm{H} 2)$ are used to get the fuel to the proper viscosity, a process controlled by the viscosity control system, known as the "viscometer".

\section{DETERMINATION OF QUALITATIVE IMPORTANCE MEASU- RES}

The reliability and functional structures of the system that allow determination of measurement streams for the individual components included in the box are shown as a block diagram in Figure 5. System components are marked according to Figure 3. The structure also includes energy streams in the form of the steam power supply (para) and electricity (el.). Nodes marked with circles containing the consecutive numbers $1 \div 6$ are: initial, final and intermediate (collective nodes and system bifurcations). The squares are symbols for the system components, all markings are the same as in Fig. 3. A detailed description is shown in Table 3.
The fault tree model associated with the system structure is shown in Figure 6 . This fault tree is used to obtain the values of measures: $\mathrm{I}_{i}^{F T A}, \mathrm{I}_{i}^{B s}, \mathrm{I}_{i}^{O}$.

The relationships summarized by Equations (4) (5) (7) and (9) allow the determination of importance measures based on the example described above. The results for individual components are shown in Table 3.

The initial reliability model does not take the type of reserves (in use, offline, or ready for duty) into account. For proper operation, the system requires an up state, such as one of the circulation pumps (P1, P2) and one of the fuel heaters $(\mathrm{H} 1, \mathrm{H} 2)$. The valves in the system are marked $\mathrm{Z} 1$ to Z11. The reliability structure is mixed, including components for the bridge joints reliability structure. Measures have been performed using CARA Fault Tree 4.1. Academic Version software produced by Sydvest Software company. An analysis made using Reliability Workbench 10 software by Isograph company revealed a convergence of results.

The results of a qualitative Fault Tree analysis are the following set of minimum cutsets:

$$
\Omega=\left\{\begin{array}{l}
\{\mathrm{Z} 10\},\{\mathrm{Z} 11\},\{\mathrm{Z} 1, \mathrm{Z} 3\},\{\mathrm{Z} 1, \mathrm{P} 2\},\{\mathrm{Z} 1, \mathrm{Z} 4\},\{\mathrm{P} 1, \mathrm{Z} 3\},\{\mathrm{P} 1, \mathrm{P} 2\},\{\mathrm{P} 1, \mathrm{Z} 4\},\{\mathrm{Z} 2, \mathrm{Z} 3\}, \\
\{\mathrm{Z} 2, \mathrm{P} 2\},\{\mathrm{Z} 2, \mathrm{Z} 4\},\{\mathrm{Z} 7, \mathrm{Z} 5\},\{\mathrm{H} 2, \mathrm{Z} 5\},\{\{\mathrm{Z} 8, \mathrm{Z} 5\},\{\mathrm{Z} 7, \mathrm{H} 1\},\{\mathrm{H} 2, \mathrm{H} 1\}, \\
\{\mathrm{Z} 8, \mathrm{H} 1\},\{\mathrm{Z} 7, \mathrm{Z} 6\},\{\mathrm{H} 2, \mathrm{Z} 6\},\{\mathrm{Z} 8, \mathrm{Z} 6\},\{\mathrm{Z} 1, \mathrm{Z} 9, \mathrm{Z} 7\},\{\mathrm{Z} 1, \mathrm{Z} 9, \mathrm{H} 2\},\{\mathrm{Z} 1, \mathrm{Z} 9, \mathrm{Z} 8\}, \\
\{P 1, \mathrm{Z} 9, \mathrm{Z} 7\},\{\mathrm{P} 1, \mathrm{Z} 9, \mathrm{H} 2\},\{P 1, \mathrm{Z} 9, \mathrm{Z} 8\},\{\mathrm{Z} 2, \mathrm{Z} 9, \mathrm{Z} 7\},\{\mathrm{Z} 2, \mathrm{Z} 9, \mathrm{H} 2\},\{\mathrm{Z} 2, \mathrm{Z} 9, \mathrm{Z} 8\}, \\
\{\mathrm{Z} 3, \mathrm{Z} 9, \mathrm{Z} 5\},\{\mathrm{Z} 3, \mathrm{Z} 9, \mathrm{H} 1\},\{\mathrm{Z} 3, \mathrm{Z} 9, \mathrm{Z} 6\},\{P 2, \mathrm{Z} 9, \mathrm{Z} 5\},\{P 2, \mathrm{Z} 9, \mathrm{H} 1\},\{P 2, \mathrm{Z} 9, \mathrm{Z} 6\}, \\
\{\mathrm{Z} 4, \mathrm{Z} 9, \mathrm{Z} 5\},\{\mathrm{Z} 4, \mathrm{Z} 9, \mathrm{H} 1\},\{\mathrm{Z} 4, \mathrm{Z} 9, \mathrm{Z} 6\}
\end{array}\right\}
$$




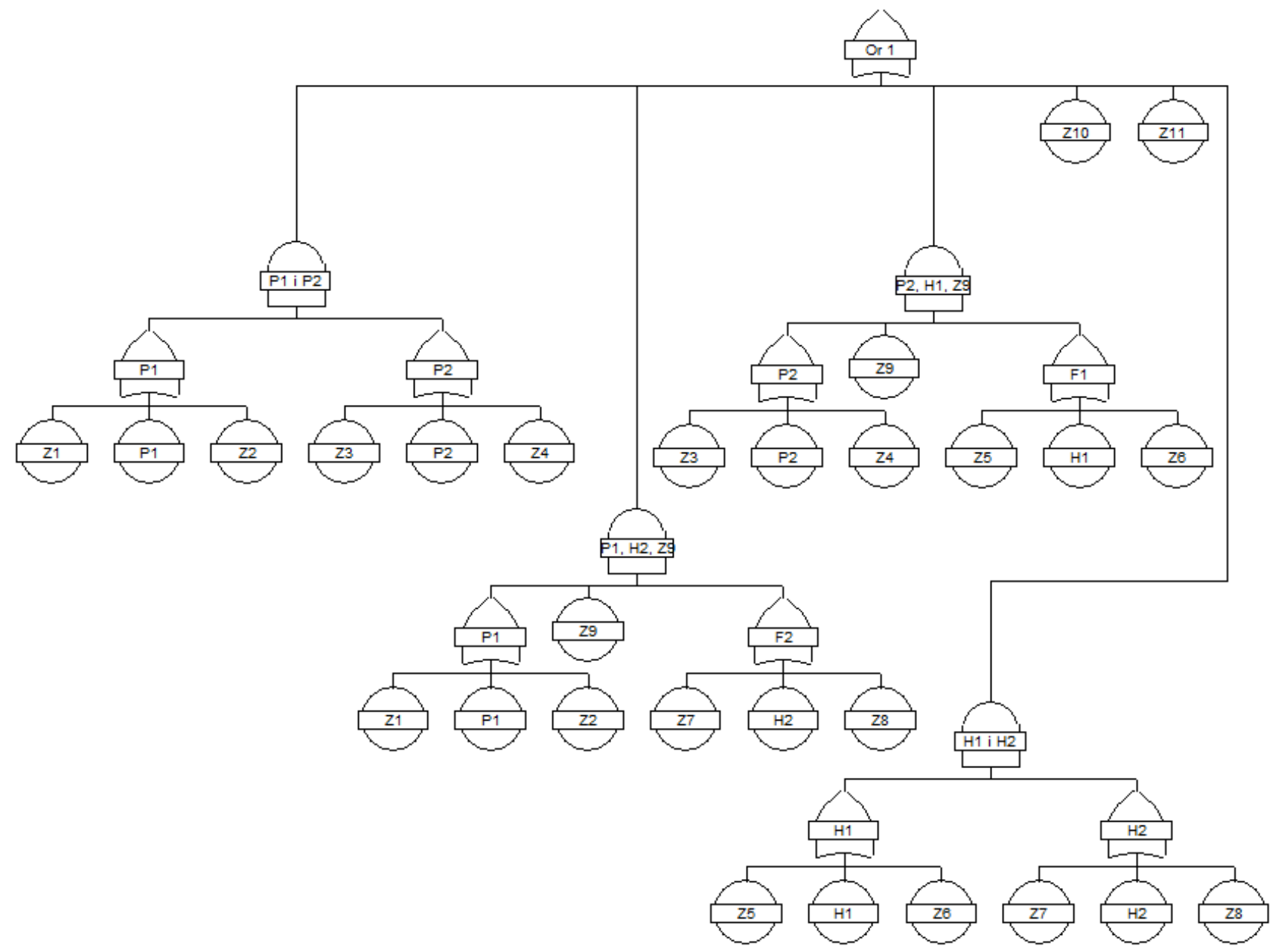

Fig. 6 Fault Tree of circulation pumps and fuel heaters subsystem for a 6500 TEU container ship main engine fuel system (description in the text)

Source: [4].

Table 3

Summary results of qualitative importance analysis of heater and circulation pump subsystem for main engine fuel supply

\begin{tabular}{|c|c|c|c|c|c|}
\hline Component marking & Component description & $I_{i}^{F T A}$ & $I_{i}^{B s}$ & $I_{i}^{O}$ & $I_{i}^{C M}$ \\
\hline $\mathrm{Z1}$ & Cut-off valve & 6 & 0.01025 & 2 & 2 \\
\hline $\mathrm{Z2}$ & Cut-off valve & 6 & 0.01025 & 2 & 2 \\
\hline $\mathrm{Z3}$ & Cut-off valve & 6 & 0.01025 & 2 & 2 \\
\hline Z4 & Cut-off valve & 6 & 0.01025 & 2 & 2 \\
\hline $\mathrm{Z5}$ & Cut-off valve & 6 & 0.01025 & 2 & 2 \\
\hline Z6 & Cut-off valve & 6 & 0.01025 & 2 & 2 \\
\hline $\mathrm{Z7}$ & Cut-off valve & 6 & 0.01025 & 2 & 2 \\
\hline Z8 & Cut-off valve & 6 & 0.01025 & 2 & 2 \\
\hline 29 & Crossover valve & 18 & 0.00598 & 3 & 4 \\
\hline $\mathrm{Z10}$ & Cut-off valve & 1 & 0.02148 & 1 & 2 \\
\hline $\mathrm{Z} 11$ & Cut-off valve & 1 & 0.02148 & 1 & 2 \\
\hline $\mathrm{P} 1$ & Fuel circulation pump no 1 & 6 & 0.01025 & 2 & 3 \\
\hline P2 & Fuel circulation pump no 2 & 6 & 0.01025 & 2 & 3 \\
\hline $\mathrm{H} 1$ & Fuel heater no 1 & 6 & 0.01025 & 2 & 3 \\
\hline $\mathrm{H} 2$ & Fuel heater no 2 & 6 & 0.01025 & 2 & 3 \\
\hline
\end{tabular}

\section{SCALED IMPORTANCE MEASURES}

Limited applicability of different measures of importance (e.g. because of lack of information on the system characteristics, unknown reliability function) and difficulties in describing complex technical systems fully and accurately make it necessary to create methods which would select a set of important components in the system according to defined criteria of importance. Different measures (different assumptions) are used to evaluate importance and they yield different results. Authors are trying to combine different qualitative methods to receive more accurate measures and this is the main purpose behind this paper.

In order to make the comparative analysis easier and to ensure that higher values for the importance metric are associated with more important components, the following 
quality-adjusted importance measures, with a [0.1] range of values, are proposed:

- the corrected order of smallest fault cutset of the i-th component is [4]:

$$
I_{i}^{C-O}=\frac{\min _{k=1,2 \ldots n^{(}}\left(I_{k}^{O}\right)}{I_{i}^{O}}
$$

where:

$\mathrm{I}_{i}^{O}$ - order of the smallest minimal cut-set containing the i-th component,

- the corrected occurrence count of the i-th component in the Fault Tree is [4]:

$$
I_{i}^{C-F T A}=\frac{I_{i}^{F T A}}{\max _{k=1,2 . . n}\left(I_{k}^{F T A}\right)}
$$

where:

$\mathrm{I}_{i}^{F T A}$ - occurrence count of an event describing the fault of the i-th component in the Fault Tree, and

- the corrected measure of the $\mathrm{i}$-th component streams is [4]:

$$
I_{i}^{C-K M}=\frac{I_{i}^{K M}}{\max _{k=1,2 . . n}\left(I_{k}^{K M}\right)}
$$

where:

$\mathrm{I}_{i}^{K M}$ - the streams measure of the i-th component.

A comparison of the qualitative importance rankings using the measures adjusted according to Equations (8), (9) and (10) and Birnbaum's structural measures is shown in Figure 7.

Because of different definitions and assumptions, various measures generate different importance rankings, which should always be taken into account when interpreting the results of the component importance analysis.

Considering the number of cooperations between components and subsystems, valve $\mathrm{Z9}$ is the most important while considering the component whose failure will cause the failure of the whole system, valve Z10 and Z11 are critical. Taking into account interactions between the analysed system and other systems (the number of inputs and outputs of energetic streams, e.g. cooling water, steam, electric supply etc.), valve $Z 9$ is the most important followed by equally important circulation pumps and fuel heaters to end with the rest of components.

An objective analysis of relationships in the system could make use of the measure proposed by the author, taking the location of the component in the structure and the functional reliability of the system into account, as shown below [4]:

$$
I_{i}^{C-N F}=\frac{I_{i}^{C-F T A}+I_{i}^{C-K M}+I_{i}^{C-O}}{\max _{k=1,2 . . . n}\left(I_{k}^{C-F T A}+I_{k}^{C-K M}+I_{k}^{C-O}\right)}
$$

Figure 8 summarizes the I values of measurement for the subsystem's individual components from the example described above - the circulation pumps and heaters in the fuel system for the ship's main propulsion engine.

The result of the qualitative importance analysis shown in Figure 4, with the criterion of using the component's location in the functional and reliability structure to indicate its importance, show an importance order topped by the $Z 9$ shunt valve, followed by circulation pumps (P1, P2) and heaters $(H 1, H 2)$, then $\mathrm{Z} 10$ and $\mathrm{Z} 11$ cut-off valves placed in series in the reliability structure, with the last position being held ex aequo by other valves $(Z 1, Z 2, Z 3, Z 4, Z 5, Z 6$, $\mathrm{Z7}, \mathrm{Z8}$ ) of the analysed structure.

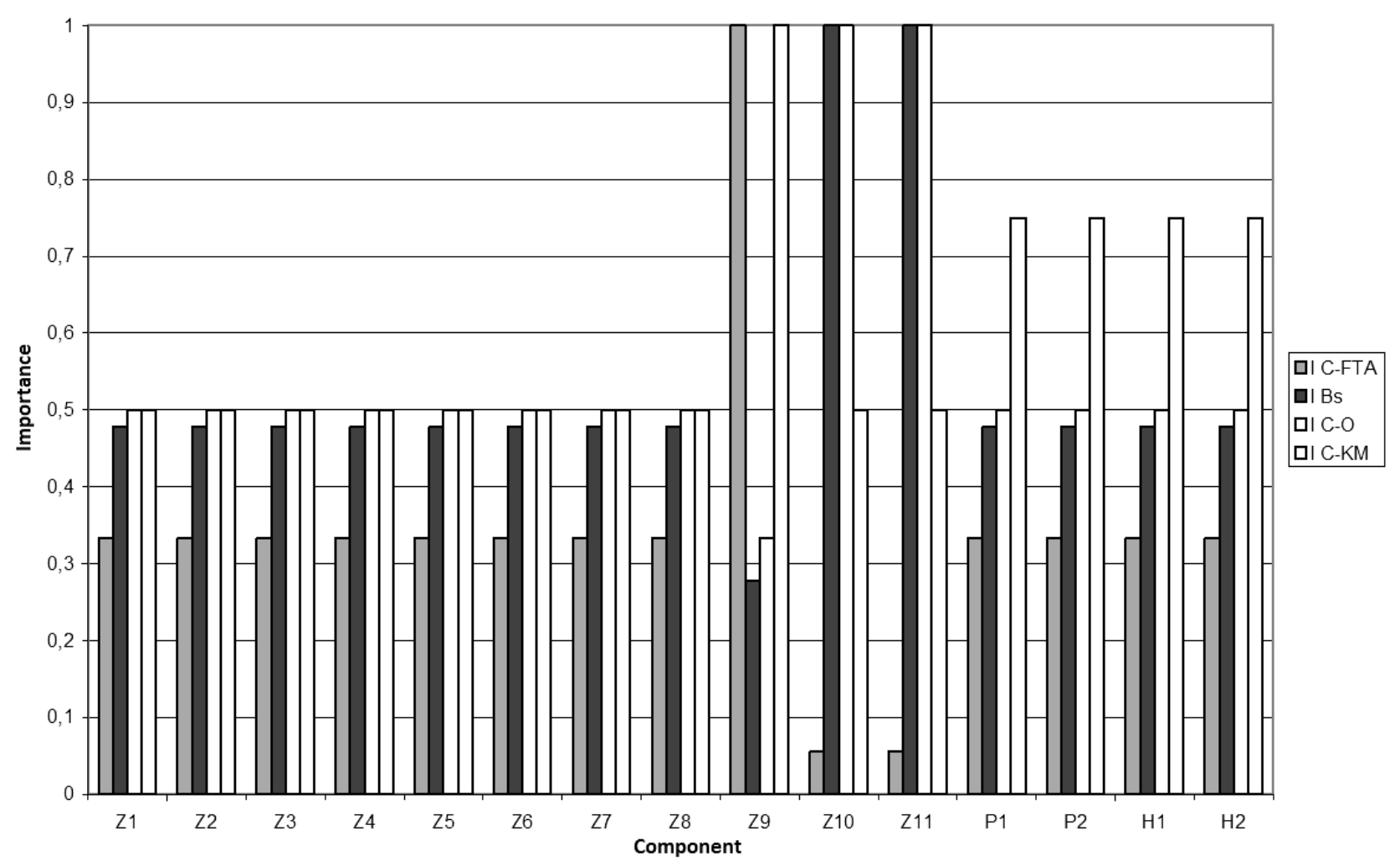

Fig. 7 Corrected values of qualitative importance measures compared with Birnbaum's structural measures Source: [4]. 


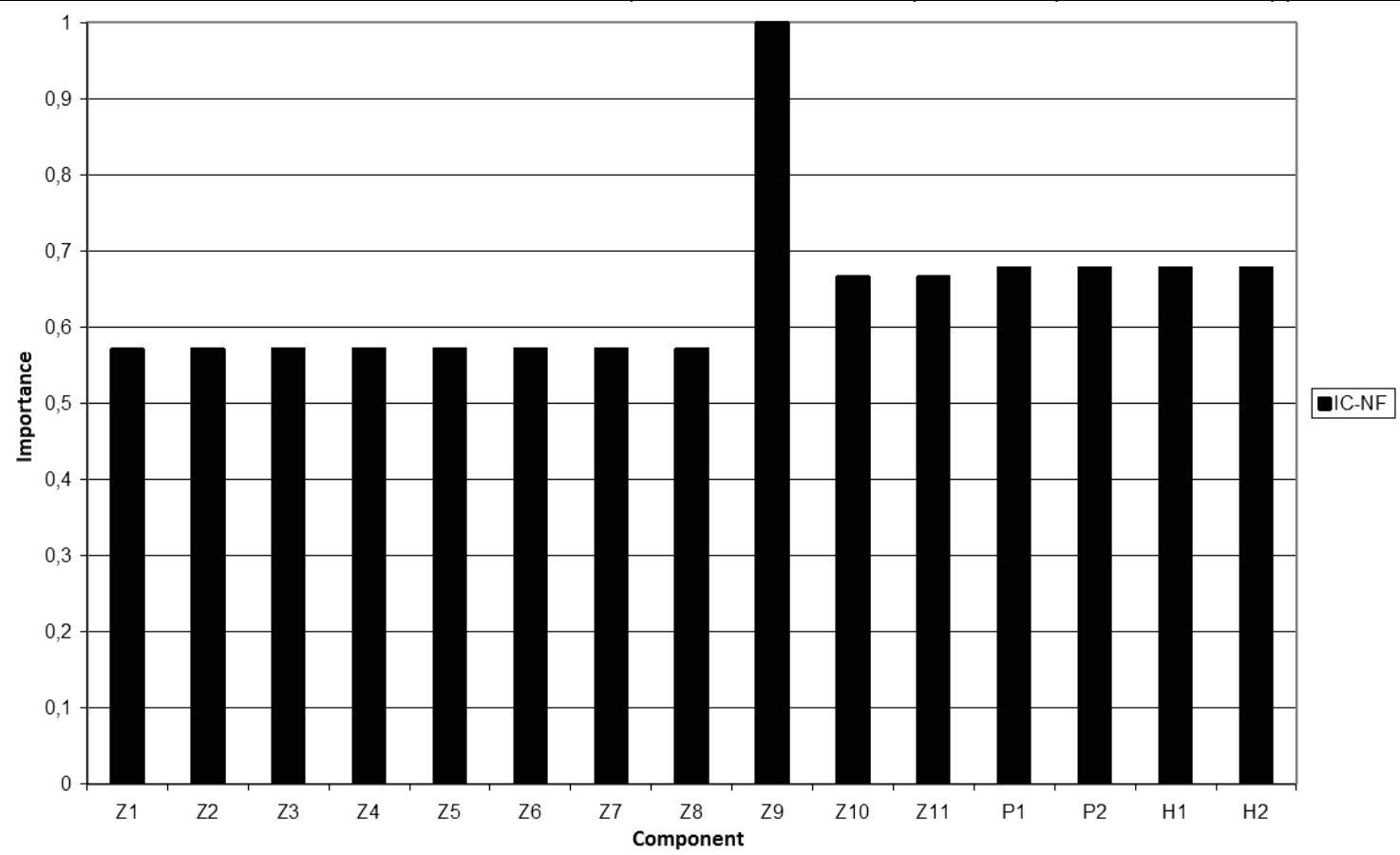

Fig. 8 Comparison of component importance relative to their location in the functional and reliability structure of the system Source: [4].

\section{CONCLUSIONS}

The chain which is as reliable as its weakest link is the symbol of reliability and safety for a technical system consisting of many components/subsystems. This model, however, is seldom true for today's machinery where elements composing a whole are not connected in series but become a complex multifunctional structure. Moreover, it is all too often the case that taking into account different evaluation criteria it turns out that not always the "weak links" are the most significant for sustaining the proper quality of the operational process. High reliability of technical systems is certainly a precondition for their safe and effective exploitation.

There is often a need for increasing the system reliability by modifying the system's structure or improving the reliability of selected components. Reliability theory concentrates on intact system operation and allows for estimating measure values that describe absence of susceptibility to damages, availability and exploitation safety. With regard to a system as a whole, basic dependability measures carry information connected with the intact system operation but as far as system components go, these measures provide very general information on their vulnerability and, except for a series reliability structure, are unable to describe the impact of a component on the whole system. The impact of the components on the system i.e. system tolerance for its components' failure, is both connected with components dependability characteristics and system structure where a particular component is located. The description of the qualitative measures of a component's importance described above can be used for complex technical systems during the initial assessment of the impact of individual fault cutsets on system functionality.

Reassuming, in the paper we:

- introduced a common measure for analysing qualitative importance,

- improved the methodology of analysing the qualitative importance of components,
- compared different measures of qualitative importance,

- introduced corrected measures for multicriteria analysis,

- proposed applications for the methodology.

In the absence of quantitative data on system failures, qualitative measures of the analysed objects' specificity, which are sets of very low quantity in case of seagoing vessels, can also be useful [9].

The specificity of a marine system's design (sharing various components in multiple minimal cut-sets) can also lead to a preliminary assessment of system functionality based on reliability structure of the system. It is useful where probabilistic data is unavailable. This is due to the existence of backup solutions in such systems, for which measures (4-9) and (11-14) are useful.

\section{Acknowledgments}

The research was carried out under a grant of the Ministry of Science and Higher Education of Poland 4/S/ITESO/14: "Diagnostics methods and efficient operation of complex technical systems in terms of failure prevention and environmental protection".

\section{REFERENCES}

[1] J. D. Andrews. „Birnbaum and criticality measures of component contribution to the failure of phased missions", in Reliability Engineering and System Safety, vol. 93, 2008, pp. 1861-1966.

[2] Z.W. Birnbaum. „On the importance of different components in a multicomponent system", Multivariate analysis-II, New York, Academic Press, 1969, pp. 581592.

[3] E. Borgonovo et al. „Comparison of global sensitivity analysis techniques and importance measures in PSA", in Reliability Engineering and System Safety, vol. 79, 2003, pp. 175-185. 
[4] L. Chybowski. Ważność elementów w strukturze złożonych systemów technicznych. Radom: Instytut Technologii Eksploatacji, 2014.

[5] L. Chybowski and R. Grzebieniak. „Aplikacje analizy drzewa niezdatności do oceny bezpieczeństwa i niezawodności systemów okrętowych na tle innych gałęzi przemysłu", in Надежность и эффрективность технических систем. KGTU, Kaliningrad 2006, pp. 51 $-59$.

[6] L. Chybowski et al. „An engine room simulator as an educational tool for marine engineers relating to explosion and fire prevention of marine diesel engines", in Scientific Journals of the Maritime University of Szczecin, no. 43(115), 2015, pp. 15-21, doi: 10.17402/034.

[7] L. Chybowski, R. Laskowski and K. Gawdzińska. „An overview of systems supplying water into the combustion chamber of diesel engines to decrease the amount of nitrogen oxides in exhaust gas", in Journal of Marine Science and Technology, vol. 20(3), 2015, pp. 393-405, doi: 10.1007/s00773-015-0303-8.

[8] L. Chybowski and S. Żółkiewski. „Basic reliability structures of complex technical systems”, in New Contributions in Information Systems and Technologies. Advances in Intelligent Systems and Computing, vol. 354, Eds. Alvaro Rocha, Ana Maria Correia, Sandor Costanzo, Luis Paulo Reis. Springer International Publishing, 2015, pp. 333-342, doi: 10.1007/978-3-319-16528 -8 31.

[9] A. Copeland and D. Agosto. „Diagrams and Relational Maps: The Use of Graphic Elicitation Techniques with Interviewing for Data Collection, Analysis, and Display", in International Journal of Qualitative Methods, vol. 11(5), 2012, pp. 513-533.

[10] C. Ericson II. „Fault Tree Analysis - A History”, in Proc. of The 17th International System Safety Conference, Unionville, Canada, 1999, pp. 1-9.

[11] J.F. Espiritu, D.W. Coit and U. Prakash. „Component criticality importance measures for the power industry", in Electric Power Systems Research, vol. 77(5-6), 2007, pp. 407-420.

[12] K. Gawdzińska, L. Chybowski and W. Przetakiewicz. „Proper matrix-reinforcement bonding in cast metal matrix composites as a factor of their good quality", in Archives of Civil and Mechanical Engineering, vol. 16 (3), 2016, pp. 553-563, doi: 10.1016/ j.acme.2015.11.004.

[13] P. Hilber and L. Bertling. „Monetary Importance of Component Reliability in Electrical Networks for Maintenance Optimization", in Proc. Probability Methods Applied to Power Systems, Ames, USA, 2004, pp. 150-155.

dr hab. inż. Leszek Chybowski,

dr hab. inż. Katarzyna Gawdzińska prof. AM

Maritime University of Szczecin, Faculty of Marine Engineering

ul. Wały Chrobrego 1-2, 70-500 Szczecin, POLAND

tel. +48914809412

e-mail: I.chybowski@am.szczecin.pl

k.gawdzinska@am.szczecin.pl

dr inż. Bogusz Wiśnicki

Maritime University of Szczecin,

Faculty of Economics and Transport Engineering

ul. Pobożnego 11, 70-507 Szczecin, POLAND

e-mail: b.wisnicki@am.szczecin.pl
[14] M.J. Juran and A.B. Godfrey. The Juran's Quality Handbook, 5th ed., New York: The McGraw-Hill Companies, 1999.

[15] K. Kim and S. Han. „A study on importance measures and a quantification algorithm in a fire PRA model", in Reliability Engineering and System Safety, vol. 94, 2009, pp. 969-972.

[16] R. Kolman. Sterowanie jakościq wytwarzania. Politechnika Gdańska, Gdańsk 1994.

[17] M. Kołdziejski and Z. Matuszak. „Estimating of the importance of element in multicomponent technical power plant system", in Materials from International Conference on Engineering Design, vol. 3, 1995, pp. 1154-1155.

[18] W. Kostrzewa, K. Gawdzińska and A. Bejger. „The use of Pareto-Lorenz analysis for the determination of faults in fishing vessel refrigerating systems", in Zeszyty Naukowe Akademii Morskiej w Szczecinie, vol. 36.1(108), 2013, pp. 90-93.

[19] W. Kuo and X. Zhu. Importance measures in reliability, risk, and optimization. Principles and applications, United Kingdom: John Wiley \& Sons Ltd., 2012.

[20] R. Laskowski, L. Chybowski and K. Gawdzińska. „An engine room simulator as a tool for environmental education of marine engineers", in New Contributions in Information Systems and Technologies. Advances in Intelligent Systems and Computing, vol. 354, Eds. Alvaro Rocha, Ana Maria Correia, Sandor Costanzo, Luis Paulo Reis. Springer International Publishing, 2015, pp. 311-322, doi: 10.1007/978-3-319-16528-8_29.

[21] M. Rausand and A. Høyland. System Reliability Theory: Models, Statistical Methods, and Applications, United Kingdom: John Wiley \& Sons Ltd., 2004.

[22] Specifications for 6,500 TEU class container carrier, Hyundai Heavy Industries, Ulsan 2003.

[23] R. Stareńczak. Statystyki wypadków na morzu w 2012 roku, a utrzymujqcy się trend spadkowy [Online]. Available: http://www.portalmorski.pl/statki/wypadkiratownictwo-sar/34012-poprawa-bezpieczenstwastatkow-i-zeglugi

[24] R. Stephans. System Safety for the 21st Century, United Kingdom: John Wiley \& Sons Ltd., 2004.

[25] J. Vatn. „Finding minimal cut sets in fault tree”, in Reliability Engineering and System Safety, vol. 36, 1992, pp. 59-62.

[26] W. Vesely et al. Fault Tree Handbook with Aerospace Applications, NASA, 2002.

[27] M. Woropay. Metoda budowy wielopoziomowych systemów do badania niezawodności z elementów o wyznaczonej a piori istotności. Rozprawy nr 18, ATR, Bydgoszcz 1983

[28] S.M. Zanoli, G.J. Astolfi and J. Marczyk. „Complexitybased methodology for Fault Diagnosis: application on a centrifugal machine", in 3rd IFAC Conference on Analysis and Control of Chaotic Systems, vol. 3, Part 1. Cancún, 2012, pp. 51-56, doi: 10.3182/20120620-3MX-3012.00060.

[29] J. Żurek, M. Zieja and Z. Smalko. „The Reliability Estimation Of Structural Components With Some Selected Failure Model", PSAM11 \& ESREL, Helsinki 25-29 June 2012. 